

\section{Autism, Creativity and Aesthetics}

Ilona Roth

\section{Affiliation}

Dr llona Roth, BA (Hons), DPhil, BA (Hons) Hum (Open), CPsychol, AFBPsS

Senior Lecturer in Psychology, School of Life, Health and Chemical Sciences, The Open University

\section{Contact details}

School of Life, Health and Chemical Sciences, STEM Faculty,

The Open University,

Walton Hall, Milton Keynes,

MK 7 6AA, United Kingdom

Ilona.Roth@open.ac.uk

\section{Biographical note}

Ilona Roth is Senior Lecturer in Psychology, School of Life Health and Chemical Sciences, The Open University. With background in cognitive psychology, she has teaching and research specialisms in autism. Roth's longstanding personal and professional interest in the arts led her recently to complete a degree in Humanities and Romance languages.

She is author of film, multi-media and written material on autism, including Roth et.al. (2010) 'The Autism Spectrum in the $21^{\text {st }}$ Century: Exploring Psychology, Biology and Practice'. She chairs the Open University online course 'Understanding the Autism Spectrum', studied by over 6500 students to date.

Roth's research on cognition and autism embraces a broader interdisciplinary focus on imagination, creativity and aesthetics, reflected, for instance, in an edited collection, 'Imaginative Minds', for the British Academy (2007), and ongoing collaboration with The Centre for Cognition, Kinesthetics and Performance at the University of Kent. 
Her work also has a cross-cultural dimension in her collaboration with The Open University and Addis Ababa University project team researching autism in Ethiopia and developing training resources for rural health workers.

\section{Key Words}

Autism; creativity; talent; outsider art; poetry; aesthetics;

\section{Acknowledgements}

The British Academy funded Ilona Roth's research project 'Imagination and Awareness of Self in Autism Spectrum Poets' (2005-2006; SG-40948), her work convening the 'Imaginative Minds' symposium (2004) and editing the 'Imaginative Minds' volume (2007).

Grateful thanks to William Aslet, Peterhouse College, Cambridge University, for discussion of the 'vedutisti', and to Nicola Shaughnessy and Melissa Trimingham at University of Kent, for ongoing dialogues about autism and creativity. 
Title: Autism, creativity and aesthetics

\section{Creativity of a different kind}

Repeat, repeat, repeat

Images replicated with consummate care

Safety in numbers

Symphony of sameness.

Forms fondly followed

No stone left unturned

In the quest for precision

And definitive depiction.

With novelty and

Fecund fantasy as

Customary hallmarks

Of creativity,

What space is there for

The meticulous mark-making

Of an autistic artist?

Yet there is originality,

Beauty and intrigue

In these images,

Surprise in the familiar

Rendered strange by

Iteration or reflection.

Creativity of a different kind. 
The potential for creative imagination in people with autism is a matter of interest and debate (Roth 2007; 2011; Trimingham et.al (in press)). The diagnostic criteria for autism, with their emphasis on restricted and repetitive behaviour and interests (American Psychiatric Association 2013), promote the view that creativity is likely to be limited in people with autism. Yet a small number of people on the autism spectrum show exceptional artistic talent and a much wider group engage in activities typically associated with creative expression, including visual art, music and theatre.

An apparently straightforward way to reconcile talented work by autistic artists with mainstream models of autistic thinking which question the likelihood of creativity, is, precisely, to attribute the work to 'talent' - even 'savant talent', implicitly aligning it with mental processes other than creativity. It is claimed, for instance, that the artist Stephen Wiltshire, has an exceptional visual memory, which enables him to glance briefly at complex architectural scenes and reproduce them accurately (Sacks 1995). This may well be correct, but tends to compartmentalise Wiltshire's gift as memory-based rather than creative. $17^{\text {th }}$ century Italian artists such as Canaletto and Pannini are celebrated by art historians for their exquisite 'vedute' - views of cities like Venice, characterised by meticulous attention to form, layout and perspective. Stephen Wiltshire has produced striking architectural drawings of some of the same buildings as Canaletto (Figs. 1 and 2). His works are black and white drawings, not paintings, and frequently lack human figures conveying scale and social context. But the flair for depicting architectural form is incontestable. Wiltshire's unusual corner view of the Doge's palace in Venice (Fig 3) is a particularly sensitive drawing with a touch almost like lacework, speaking eloquently to the delicate character of the façade. Yet Wiltshire is celebrated perhaps as much for 'savantism'- prodigious talent in the context of disability (Treffert 2009) - as for artistry as such.

A related pigeon hole is 'outsider art'. This is Roger Cardinal's translation of 'art brut', the term coined by Dubuffet to denote art by untrained artists 'created outside the boundaries of official culture' (Cardinal 1972; 2009). The recognition of outsider art, and the galleries which specialise in 
such work, have achieved much that is highly positive in bringing work by autistic artists and others to wider public attention (McKenzie 2011). But 'outsider art' may also perpetuate the boundary between an 'in-group' which inhabits and defines the realm of official culture and others who work outside it. This makes it harder for autistic art to be considered on its own merits, side by side with artistic work by neurotypical (non-autistic) artists. Yet as noted by Cardinal 'these works deserve respect as meaningful and intentional artistic compositions.' (Cardinal 2009 op.cit.).

A third 'containment vessel' is genre - the idea that autistic artworks are likely to share certain specific characteristics, again attributable to the condition, rather than to individual artistic flair. I explored this idea some years ago in a study of poetry by autistic writers (Roth 2007; 2008). My aim at the time was to clarify the apparent disjunct between the capacity to write poetry, and influential theories about 'cognitive style' in people with autism. Baron-Cohen, for instance, has argued for a distinctive cognitive style typically combines high levels of 'systemising' - the drive to extract rules and regularities from systems, with low levels of empathising - the ability to understand other people's feelings and respond appropriately (Baron-Cohen 2009). This profile, it is argued, means that people with autistic traits are more likely to favour and to succeed in the sciences, mathematics and technology, than in the arts and humanities (Baron-Cohen et.al. 2001). This model does not readily accommodate the fact that some people with autism prefer expressing themselves in poetry to engaging with machines or equations. Yet it could perhaps be that autistic poets adopt a systemising approach to their poetry, embracing poetic 'craft' (for instance, the use of devices such as rhyme, rhythm and alliteration), but not the 'art' of playing imaginatively with figurative language and expressing emotions?

To explore the imaginative and expressive qualities of autistic poetry, poems by five autistic writers were analysed line by line for number and type of metaphors and other figurative language and for use of mental state terms ('I think', 'you feel' and so on). The use of poetic devices, including rhyme, rhythm, alliteration and assonance was documented and the poetry themes were categorised. 
Similar analyses were conducted for work by neurotypical poets, matched as far as possible for age and educational level with the autistic poets.

Evidence for an identifiable 'genre' of poetry was mixed. Much of the poetry showed a predominant self-focus, both thematically and in using self-directed mental state language (e.g. 'I think'; I feel') rather than other-focused mental state language ('You think'; 'you feel). Moreover, one poet wrote mostly in regular rhyming couplets, using few metaphors or other figurative language. But the other poets wrote in free verse and used metaphors fairly freely, and several of them certainly engaged with fantastical ideas and images.

In short, while this study highlighted interesting commonalities among the works of the autistic poets- notably a frequent focus on self in both language and themes - no single genre encapsulated all this poetry. There were many forms of imaginative expression, and little evidence for 'writing by rules'. Similarly, while some autistic visual art displays characteristic features consistent with one particular autistic 'cognitive style', the body of work as a whole defies an overly unified portrayal. Mullin's excellent collection 'Drawing Autism' (Mullins 2009) devotes a section to repetition, and another to transport, two attributes which are broadly consistent with the idea of 'systemising'. But the collection also features cartoon-like works, abstract paintings, figurative drawings and surreal scenes.

If, then, there is no unified autistic style in the visual arts, why does my own poem for this paper evoke two motifs- repetition and realism - often considered quintessentially autistic? My point is that when features such as these do appear in autistic artwork they invite a wider examination of our core assumptions about creativity. Notably, repetition might seem the very opposite of originality, leading us to exclude from the creative canon works which involve repeats of familiar images. But, as in evaluations of Wiltshire's realist works, this could reflect a double aesthetic standard (Roth op.cit.). Consider the work of the American artist, Gregory Blackstock, which is replete with repeating images, identical, or with systematic variations achieved for instance, by 
modulating colour and pattern (Fig. 4), or by juxtaposing related species of animals (Fig. 5). A 'systemising' approach to art perhaps, but also a striking fusion of traditional zoological illustration (think 'Voyage of the Beagle') with Warhol-like pop art. Warhol was hailed as a creative genius precisely on account of works composed of repeated familiar images, often with systematic modulation from one to the next, as in his screen prints of Marilyn Monroe and the iconic soup cans (Fig. 6).

Some might seek to elevate the creativity of Warhol's work by invoking artistic intentions akin to those of the earlier artist Duchamp, who set out deliberately to challenge prevalent criteria of creativity and to subvert aesthetic values, notably by presenting ready-made everyday objects such as a porcelain urinal as a work of art. However, it is not clear whether Warhol himself intended his screen prints to act on the public in a similar way. Promoting image repeats of familiar faces and objects as a new form of creativity may have owed as much to the zeitgeist, and to the promotional activities of Warhol's ever-present coterie of friends and agents, as to his personal artistic aims. His friend Charles Lisanby (quoted in Fitzgerald 2005 p.2003) said:

'Andy didn't really know what he wanted to do with art at all. He was totally unfocussed. Except he had this overwhelming creative drive to do something and never stopped going.' As an intriguing twist, some accounts have suggested that Warhol may himself have had a form of autism (Fitzgerald 2005). However, no diagnosis can or should be made retrospectively.

Not all autistic artists have the exceptional gifts of Wiltshire or Blackstock. But the work of such artists opens our eyes to the fact that people across the autism spectrum may express creativity differently from standard neurotypical expectations (Roth 2014). Lest this be seen as drawing yet another line around autistic creativity, I should emphasise that my own poem 'Creativity of a different kind' takes inspiration from one of the poets I studied. In 'The Search', Romkema (1996) played most effectively- and imaginatively- with alliteration and assonance, almost as if savouring the sensory qualities of the repeating sounds. 


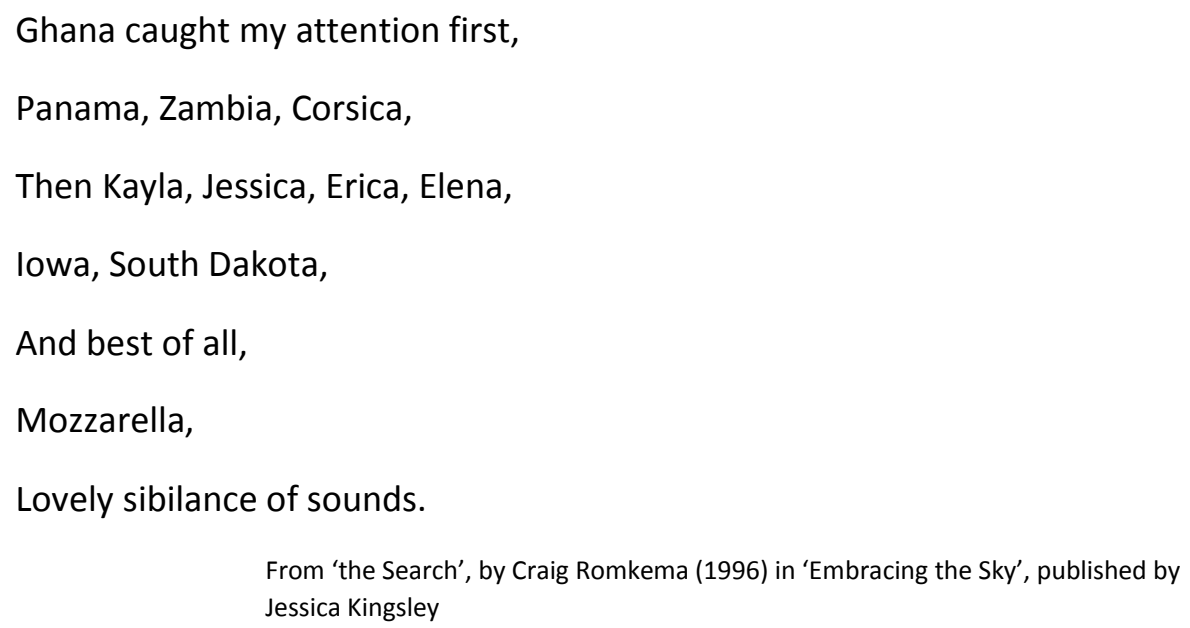

I have used alliteration and assonance- the lovely sibilance of sounds- in my own poem as an auditory expression of the special aesthetic qualities of visual likeness and repetition expressed in certain autistic art works.

My purpose in this reflection has been twofold. Firstly I have argued that evaluating the artistic techniques employed by some autistic artists highlights the capriciousness of our aesthetic judgements and the contested nature of creativity. Secondly, I have suggested that despite some common motifs, autistic art covers a complex and varied field of human endeavour which cannot purely be reduced to neuropsychological formulae.

In conclusion, we need to develop appropriate conceptual tools to understand creativity in all its forms, and to nurture the drive for creative self-expression wherever it exists. Whether artistically exceptional or not, many people on the autism spectrum engage enthusiastically with creative media, challenging the stereotype of the autistic mind as closed to spontaneous self-expression. The benefits are many. For instance, Stephen Wiltshire was mute as a child, but his drive to draw was so strong that he began speaking to ask for drawing implements (Sacks 1995 cited in Furniss 2008). For other non-speaking autistic children, visual art or music have offered alternative systems of meaning and communication. (Furniss 2008; Ockleford 2012). Roy et.al. (2004) discuss several autistic poets who speak exclusively through poetry, finding in this medium the means to transcend isolation, and 
in the process offering unique perspectives on autistic experience. Finally, the innovative 'Imagining Autism' project (Beadle-Brown et.al. (2017)) seeks to promote both creative and social imagination in autistic children through immersive engagement in drama.

\section{References}

American Psychiatric Association (2013) Diagnostic and statistical manual of mental disorders: DSM-

5. Washington, D.C: American Psychiatric Association.

Baron-Cohen, S., Wheelwright, S., Skinner, R., Martin, J., and Clubley, E. (2001) 'The AutismSpectrum Quotient (AQ): ‘Evidence from Asperger Syndrome/High-Functioning Autism, Males and Females, Scientists and Mathematicians', Journal of Autism and Developmental Disorders, vol. 31, pp. 5-17

Beadle-Brown, J.,Wilkinson, D.T., Richardson, L., Shaughnessy, N.,Trimingham, M., Leigh, J., Whelton, B., and Himmerich, J. (In Press) 'Imagining Autism: Feasibility of a Drama-Based Intervention on the Social, Communicative and Imaginative behaviour of Children with Autism', Autism: International Journal of Research

Baron-Cohen, S., (2009) 'Autism: The Empathising-Systemising (E-S) Theory', Annals of the New York Academy of Science, vol. 1156, pp. 68-80

Cardinal, R. (1972) Outsider Art, New York, Praeger

Cardinal, R. (2009) 'Outsider Art and the autistic creator', Philos. Trans. R. Soc. Lond. B. Biol. Sci. May 27; 364(1522): 1459-1466.

Fitzgerald, M. (2005) The Genesis of Artistic Creativity: Asperger's Syndrome and the Arts, Jessica Kingsley Publishers, London and Philadelphia

McKenzie R.K. (2011) 'A different way to think about creativity: the case of autism and Outsider Art', (unpublished) 
Ockelford, A. (2012) 'Songs Without Words: Exploring how Music Can Serve as a Proxy Language in Social Interaction with Autistic Children', in MacDonald, R., Kreutz, G., and Mitchell, L., (eds.) Music, Health and Well-Being, Oxford, Oxford University Press

Roth, I. (2007) 'Autism and the Imaginative Mind' in Roth, I. (ed.) Imaginative Minds, Proc. Brit. Ac. vol. 147, pp.277-306 and Oxford, Oxford University Press

Roth, I. (2008) 'Imagination and the Awareness of Self in Autistic Spectrum Poets', in Osteen, M. (ed.) Autism and Representation Routledge, New York

Roth, I. (2011) 'Strange Imagination: insights from autism', paper presented at Inspiration and the Creative Spark, the annual conference of the Institute for Cultural Research, London Roth, I. (2014) 'Imagining differently: the cognitive style in autism', paper presented at the $2^{\text {nd }}$ international conference on Cognitive Futures in the Humanities, Durham Sachs, O. (1995). An anthropologist on mars, New York, Vintage Books Treffert, D. (2009) 'Savant syndrome: an extraordinary condition. A synopsis: past, present and future', Philos. Trans. R. Soc. Lond. B. Biol. Sci. May 27; 364(1522): 1351-1357.

Trimingham, M., Shaughnessy, N. and Roth, I., (in press) 'Imagining Another: engaging with autism through contemporary performance and cognitive science', to appear in Kemp, R. (ed.), The Routledge Companion to Theatre, Performance and Cognitive Science 
Figures

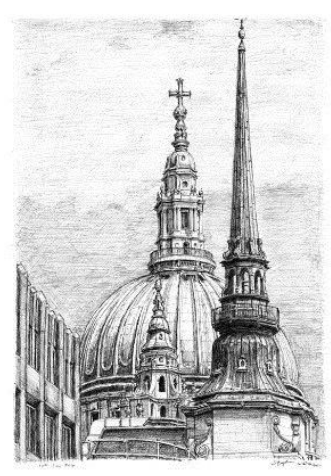

Fig. 1 Stephen Wiltshire 2010

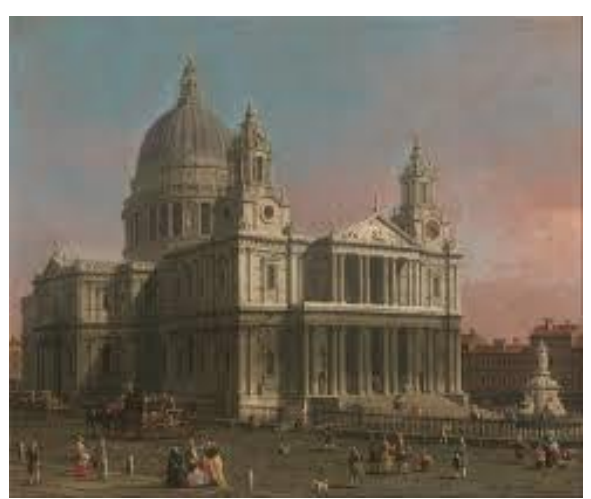

Fig. 2 Canaletto

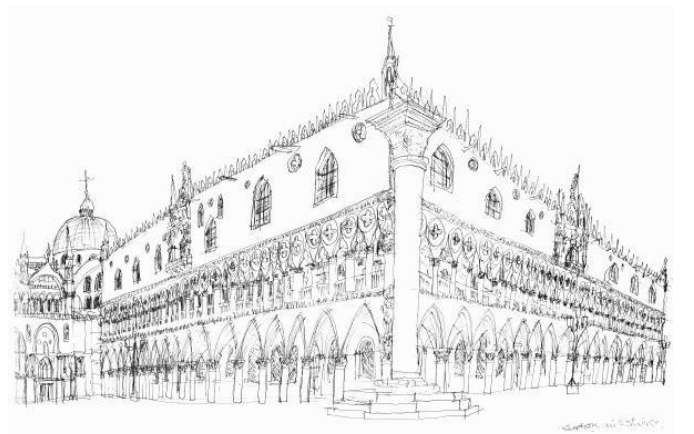

Fig.3 Stephen Wiltshire 1989

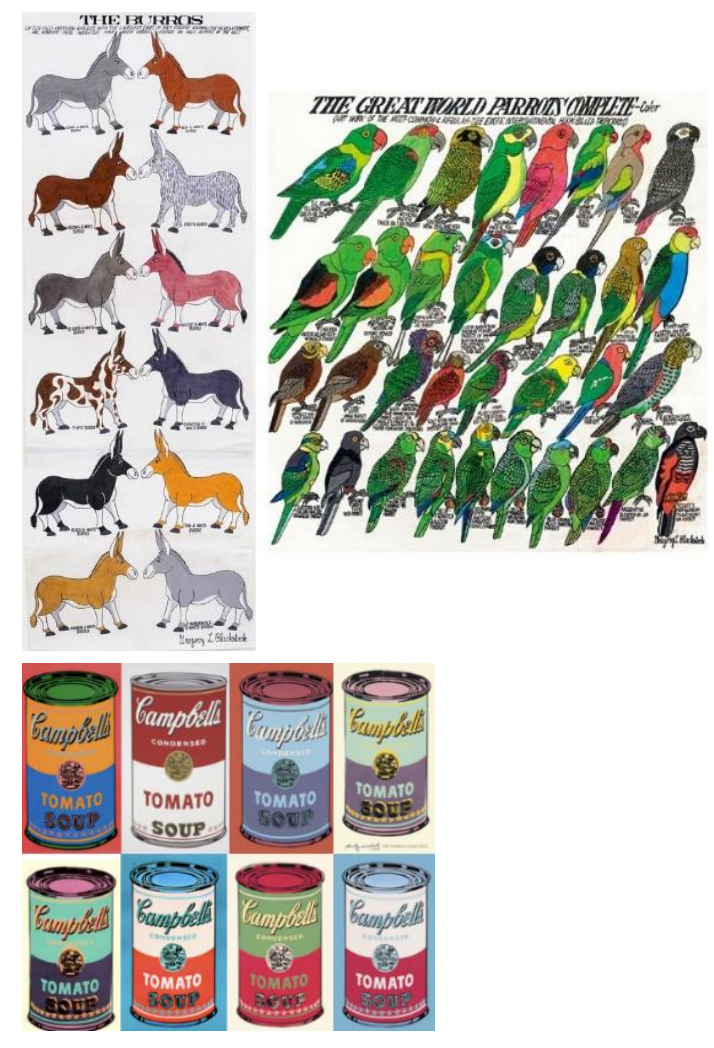

Figs. 4 and 5 Gregory Blackstock Fig. 6 Andy Warhol 
